\title{
BMJ
}

\section{Retention in the British National Health Service of medical graduates trained in Britain: cohort studies}

\author{
Michael J Goldacre, professor of public health Jean M Davidson, research officer Trevor W Lambert, \\ statistician
}

UK Medical Careers Research Group, Department of Public Health, University of Oxford, Old Road Campus, Oxford OX3 7LF Correspondence to: M J Goldacre, Unit of Health-Care Epidemiology, Department of Public Health, University of Oxford, Old Road Campus, Oxford OX7 3LF michael.goldacre@dphp.ox.ac.uk

Cite this as: $B M J$ 2009;338:b1977 doi:10.1136/bmi.b1977

\section{ABSTRACT \\ Objective To report the percentage of graduates from British medical schools who eventually practise medicine in the British NHS. \\ Design Cohort studies using postal questionnaires, employment data, and capture-recapture analysis. Setting Great Britain.}

Subjects 32430 graduates from all British medical schools in nine graduation cohorts from 1974 to 2002, subdivided into home based medical students (those whose homes were in Great Britain when they entered medical school) and those from overseas (whose homes were outside Great Britain when they entered medical school).

Main outcome measures Working in the NHS at seven census points from two to 27 years after qualification. Results Of home based doctors, $88 \%$ of men (6807 of 7754 ) and $88 \%$ of women (7909 of 8985 ) worked as doctors in the NHS two years after qualification. The corresponding values were $87 \%$ of men (7483 of 8646 ) and $86 \%$ of women ( 7364 of 8594 ) at five years; $86 \%$ (6803 of 7872 ) and $86 \%$ (5407 of 6321) at 10 years; $85 \%$ (5404 of 6331) and $84 \%$ (3206 of 3820) at 15 years; and $82 \%$ (2534 of 3089$)$ and $81 \%$ (1132 of 1395) at 20 years. Attrition from the NHS had not increased in recent cohorts compared with older ones at similar times after graduation. Of overseas students, $76 \%$ (776 of 1020) were in the NHS at two years, $72 \%$ (700 of 972$)$ at five years, $63 \%$ (448 of 717 ) at ten years, and $52 \%$ (128 of 248) at 20 years.

Conclusions The majority of British medical graduates from British medical schools practise in the NHS in both the short and long term. Differences between men and women in this respect are negligible. A majority of doctors from overseas homes remain in Britain for their years as junior doctors, but eventually about half leave the NHS.

\section{INTRODUCTION}

Training adequate numbers of physicians and retaining a high proportion of them in the medical workforce are global concerns. Policy makers need to know the extent to which medical school graduates contribute not just to long term medical practice but specifically to the national medical workforce in their country of training. ${ }^{1}$ Furthermore, as the number of women in medical training rapidly expands in many countries, it is important to investigate how the participation of women in the medical workforce compares with that of men. ${ }^{2}$ We report participation rates in the British NHS of graduates from British medical schools.

\section{METHODS}

Design

We used data from longitudinal surveys of doctors undertaken by our Medical Careers Research Group (MCRG) using postal questionnaires, supplemented by data from NHS employment records. Survey data and NHS data were analysed with capture-recapture methods, originally developed in animal ecology to estimate the total size of animal populations, ${ }^{3}$ to provide very accurate information about NHS participation. NHS posts included those held by doctors in academic posts with honorary contracts to practise medicine in the NHS.

\section{Data from UK MCRG surveys}

The study population comprised all medical graduates from all medical schools in Great Britain (England, Wales, and Scotland) who qualified in 1974, 1977, 1983, 1988, 1993, 1996, 1999, 2000, and 2002. Our methods, used in ongoing surveys, have been described elsewhere. ${ }^{4}$ In the year of qualification of each cohort, we obtained addresses from doctors' registration with the General Medical Council. We used postal questionnaires to seek information, including job histories, current employment, dates of jobs, job location, employer, specialty, and basic demographic information. Questionnaires were mailed to all graduates one year after qualification, at subsequent intervals of two years up to seven years, at 10 years, and at approximately 15 and 25 years. Reminder mailings were sent to non-respondents.

We used location of family home (Great Britain or overseas), as reported to us by the doctors, to classify each doctor as a "home" student or "overseas" student at the time of entry to medical school.

\section{Data from the Department of Health}

From employment records the English Department of Health produces an annual census of all doctors 
working in the NHS on 30 September each year. Department of Health staff specified whether each doctor was in the NHS on the census date using the doctor's General Medical Council registration number.

\section{Capture-recapture calculations}

For capture-recapture analysis, NHS employment status was classified at each census point as (a) known to both MCRG and Department of Health to be working in the NHS, (b) known to MCRG, but not to Department of Health, to be working in the NHS, and (c) known to Department of Health, but not to MCRG, to be working in the NHS. These three categories were used to calculate the size of a fourth group (d), working in the NHS, but not known as such to either the MCRG or the Department of Health, using the formula $d=b c /(a+1)$. An estimated total number $(e)$ in the NHS can then be calculated as $a+b+c+d .^{5-7}$ This value can be compared with the total of all doctors in each cohort (f), excluding the small numbers known to be deceased or who asked to be non-participants, to give the percentage of the cohort estimated to be in the NHS at each census time (e/f). The 95\% confidence interval for each percentage was estimated using the standard formula for calculating the standard error of a capturerecapture estimate..$^{5}$

We present results for particular landmark years: at two years, five years, 10 years, 15 years, 20 years, 25 years, and 27 years after graduation.

\section{RESULTS}

\section{Study population and response rate}

The initial study population comprised the 32430 doctors who graduated from British medical schools in the relevant years. After excluding 160 doctors known to be deceased at the time of the most recent survey of each cohort, and 257 who declined to participate, 32013 doctors from these cohorts (98.7\%) were included in questionnaire mailings. Responses were received from 28439 of 32013 doctors $(88.8 \%)$ on at least one occasion. Appendix 1 shows the details for individual cohorts.

Over all cohorts, we knew the family home location of 25833 of 32013 doctors (80.7\%). Of the $25833,94 \%$ (24 361) were from family homes in Great Britain and $6 \%$ (1472 doctors) were from family homes overseas. The contribution of individual cohorts of home based and overseas based doctors to the analysis for landmark years is shown in appendix 2. For the early years of the 1974, 1977 and 1983 cohorts, Department of Health data, needed for capture-recapture analysis, were not available.

\section{Participation in the NHS in Great Britain: home based graduates}

Of graduates with family homes in Great Britain, 88\% were working in the NHS in Great Britain two years after qualification (table 1). Subsequent years showed a gradual, small decline: participation was $86 \%$ in years five and $10,85 \%$ by year $15,82 \%$ by year 20 , and $81 \%$ by year 25 .

Percentage participation in the NHS by men and women was very similar. $88 \%$ of men and $88 \%$ of women were in the NHS two years after qualification. The corresponding figures were $87 \%$ of men and $86 \%$ of women at five years, $86 \%$ and $86 \%$ at 10 years, $85 \%$ and $84 \%$ at 15 years, $82 \%$ and $81 \%$ at 20 years, and $81 \%$ and $81 \%$ at 25 years. Considering individual cohorts, by five years after qualification percentage participation in the NHS was fractionally higher for men than for women in all but the 2000 cohort. Although differences between men and women were small, the number of doctors in each cohort was large, and some differences were statistically significant.

Comparing cohorts over time, we noted an increasing trend in the more recent cohorts for doctors to be employed in the NHS in the middle years after qualification (five, 10, and 15 years) (table 1), although the overall increase in percentages in the NHS was fairly small. The trend towards retention in the NHS was more evident for women than for men. Importantly, there is no evidence that younger cohorts were more inclined than older cohorts to leave the NHS; and no evidence that there were any periods of time over the past 30 years when there was any sudden loss of doctors from the NHS.

\section{Part time work: home based graduates}

Approximately $2 \%$ of both male and female home based graduates were working part time two years after qualification (men 1.6\%, 86 of 5296; women $2.2 \%, 145$ of $\left.6476 ; \chi^{2}=5.4, \mathrm{P}=0.02\right)$. Among men, part time working settled at about $5 \%$ between years five and 15 , and then increased to $9 \%$ by year 20 and $10 \%$ by year 25 . The percentages of women working part time at each stage were much higher, with more than $20 \%$ working part time at five years, $50 \%$ at $10,54 \%$ at 15 , and $47 \%$ at 25 .

Participation in the NHS in Great Britain: doctors with family home outside Britain

Participation in the NHS was significantly lower among overseas based doctors than among their home based contemporaries (table 2). For example, combining the cohorts, two years after qualification $76 \%$ of overseas based doctors were working in the NHS compared with $88 \%$ of home based doctors. The values were, respectively, $72 \%$ and $86 \%$ at five years, $63 \%$ and $86 \%$ at $10,58 \%$ and $85 \%$ at $15,52 \%$ and $82 \%$ at 20 , and $50 \%$ and $81 \%$ at 25 years. As with home based doctors, differences between men and women were small.

Destinations outside the NHS: home based graduates We subtracted the numbers of doctors in the NHS (known from capture-recapture) from the total number of doctors in the initial cohorts to give the numbers of doctors known not to be in the NHS. We then used the data from the respondents who were not in the NHS, as 
Table 1| Percentage $(95 \% \mathrm{Cl})$ of doctors from homes in Great Britain who were working in the NHS after qualification

\begin{tabular}{|c|c|c|c|}
\hline $\begin{array}{l}\text { Years after qualification, and } \\
\text { cohort }\end{array}$ & Men & Women & Total \\
\hline \multicolumn{4}{|l|}{2 years after } \\
\hline 1988 & $87.0(86.5$ to 87.4$)$ & 87.4 (87.1 to 87.7$)$ & 87.2 (86.9 to 87.4$)$ \\
\hline 1993 & 87.5 (86.9 to 88.0$)$ & 87.5 (87.0 to 88.1$)$ & 87.5 (87.1 to 87.9$)$ \\
\hline $1996^{*}$ & 87.8 (86.9 to 88.6$)$ & 90.1 (89.2 to 91.0$)$ & 89.0 (88.4 to 89.7$)$ \\
\hline 1999* & $91.0(89.5$ to 92.5$)$ & 88.6 (87.4 to 89.7$)$ & 89.6 (88.7 to 90.6$)$ \\
\hline 2000 & 87.2 (85.9 to 88.5$)$ & 87.7 (86.8 to 88.7$)$ & 87.5 (86.7 to 88.3 ) \\
\hline 2002 & 86.5 (85.2 to 87.8$)$ & 86.8 (86.1 to 87.5$)$ & 86.6 (86.0 to 87.2$)$ \\
\hline Total & 87.8 (87.4 to 88.2 ) & $88.0(87.7$ to 88.4$)$ & 87.9 (87.7 to 88.2$)$ \\
\hline \multicolumn{4}{|l|}{5 years after } \\
\hline 1983 & 85.8 (84.7 to 86.8$)$ & $83.0(81.7$ to 84.4$)$ & 84.8 (84.0 to 85.6$)$ \\
\hline 1988 & 84.4 (83.9 to 85.0 ) & 83.5 (82.7 to 84.2$)$ & 84.0 (83.5 to 84.5$)$ \\
\hline 1993 & 86.5 (85.2 to 87.7$)$ & 84.4 (83.2 to 85.5$)$ & 85.4 (84.6 to 86.3$)$ \\
\hline 1996 & 87.3 (85.9 to 88.8 ) & 83.2 (82.1 to 84.2 ) & 85.2 (84.3 to 86.1$)$ \\
\hline 1999 & 88.6 (87.3 to 89.8$)$ & 85.6 (84.6 to 86.7$)$ & 86.9 (86.1 to 87.7$)$ \\
\hline 2000 & 86.9 (85.1 to 88.7$)$ & $92.3(90.7$ to 94.0$)$ & 90.0 (88.8 to 91.2$)$ \\
\hline Total & 86.5 (86.0 to 87.1$)$ & 85.7 (85.2 to 86.2$)$ & 86.2 (85.8 to 86.5$)$ \\
\hline \multicolumn{4}{|l|}{10 years after } \\
\hline 1977 & $86.0(85.5$ to 86.5$)$ & 81.8 (80.7 to 82.9$)$ & 84.7 (84.2 to 85.2$)$ \\
\hline 1983 & $85.6(85.0$ to 86.2$)$ & 83.0 (82.0 to 83.9 ) & 84.7 (84.1 to 85.2$)$ \\
\hline 1988 & 88.1 (87.6 to 88.5 ) & 87.5 (86.9 to 88.1 ) & 87.8 (87.4 to 88.1 ) \\
\hline 1993 & 89.4 (88.1 to 90.6$)$ & 86.7 (85.5 to 87.8$)$ & $88.0(87.2$ to 88.9$)$ \\
\hline 1996 & 86.4 (84.1 to 88.6$)$ & 88.4 (86.1 to 90.6$)$ & 87.5 (85.9 to 89.1$)$ \\
\hline Total & 86.4 (86.0 to 86.8$)$ & 85.5 (85.0 to 86.1$)$ & $86.0(85.7$ to 86.4$)$ \\
\hline \multicolumn{4}{|l|}{15 years after } \\
\hline 1974 & 83.1 (82.6 to 83.7) & $82.7(81.3$ to 84.2$)$ & 83.1 (82.5 to 83.7 ) \\
\hline 1977 & 85.7 (85.0 to 86.3 ) & 82.3 (81.2 to 83.4$)$ & 84.7 (84.1 to 85.3$)$ \\
\hline 1983 & 85.6 (84.6 to 86.5$)$ & 82.0 (80.8 to 83.3 ) & 84.3 (83.6 to 85.1 ) \\
\hline 1988 & 87.2 (86.6 to 87.8 ) & $87.6(86.8$ to 88.3$)$ & 87.4 (86.9 to 87.9$)$ \\
\hline Total & 85.4 (85.0 to 85.7$)$ & 83.9 (83.4 to 84.5$)$ & 84.9 (84.6 to 85.3$)$ \\
\hline \multicolumn{4}{|l|}{20 years after } \\
\hline 1974 & 81.6 (81.0 to 82.2 ) & 82.7 (81.5 to 84.0$)$ & 82.0 (81.4 to 82.5$)$ \\
\hline 1977 & 82.5 (81.6 to 83.3 ) & 79.8 (78.2 to 81.4) & 81.5 (80.7 to 82.3 ) \\
\hline Total & $82.0(81.5$ to 82.6$)$ & 81.1 (80.0 to 82.2 ) & 81.7 (81.2 to 82.2$)$ \\
\hline \multicolumn{4}{|l|}{25 years after } \\
\hline $1974 \dagger$ & 80.0 (79.4 to 80.6$)$ & 82.0 (80.8 to 83.2 ) & 80.6 (80.0 to 81.1$)$ \\
\hline 1977 & 81.6 (80.9 to 82.4) & 79.3 (78.2 to 80.5$)$ & $80.9(80.2$ to 81.5$)$ \\
\hline Total & 80.9 (80.4 to 81.3 ) & 80.5 (79.6 to 81.4$)$ & 80.8 (80.3 to 81.2$)$ \\
\hline \multicolumn{4}{|l|}{27 years after } \\
\hline 1977 & $82.0(81.4$ to 82.7$)$ & 79.4 (77.9 to 81.0$)$ & 81.2 (80.6 to 81.7$)$ \\
\hline
\end{tabular}

Results include data from most recent survey, for doctors who indicated that their family home location is in Great Britain.

Data were not available for capture-recapture analysis for the earliest years of the oldest cohorts, as the tables indicate.

Excluded: graduates who were deceased and those who asked to be non-participants.

Our surveys included doctors who qualified in Northern Ireland. However, we do not have data for capture

recapture analysis from Northern Ireland. We have therefore omitted doctors who qualified in Northern Ireland from all analyses.

*Results are for year 3 for 1999 and 1996 cohorts.

†Results are for year 24 for 1974 cohort.
Considering doctors not in the NHS, the largest group were in medicine overseas (for example, 7\% of both men and women at year two; $9 \%$ of men and $7 \%$ of women at year 20). Doctors in medical jobs in Britain, but not in the NHS, comprised $3 \%$ of men and $1 \%$ of women in year 2 ; and $7 \%$ of men and $6 \%$ of women in year 20. Doctors who were not working in medicine at all comprised $2 \%$ of men and $4 \%$ of women in year 2 ; and $2 \%$ of men and $6 \%$ of women at year 20 .

\section{DISCUSSION}

Main findings

The great majority of British medical graduates from British medical schools practise in the NHS in both the short and long term. Differences between men and women in whether they worked in the NHS are negligible. Most doctors who were not in the NHS were in medical employment elsewhere. This finding accords with data about what junior doctors say they will do if they leave the NHS: they are much more likely to want to work in medicine elsewhere than to leave medicine. ${ }^{8}$

\section{Strengths and weaknesses of the study}

Our study provides large scale, long term longitudinal survey data about doctors in Britain. Although response rates were high, we have to consider the possibility of non-responder bias. However, the opportunity to enhance our survey data with workforce statistical records from the Department of Health, and undertake capture-recapture analysis, greatly increased the precision with which we estimated NHS participation in the cohorts. The essence of capture-recapture is to combine the results of two or more independent sources of data to produce much more precise estimates of a population than would be possible from one source alone.

Our calculations of the employment of doctors who were not in the NHS depend on applying the percentages of respondents known to be in non-NHS jobs to the numbers of non-respondents whom we knew were not in the NHS. We have no way of knowing whether the assumption that non-NHS non-respondents have a similar job distribution to non-NHS respondents is justified.

\section{Policy implications and conclusions}

A view exists that the increased intake of women to medical school may substantially reduce the percentage of qualified doctors who will eventually work in medicine. ${ }^{29}$ Our evidence from Britain does not support this view. Percentages of men and of women who eventually work in the NHS are very similar. It is true that, of graduates not employed in the NHS, a slightly higher percentage of women than men are not in medicine; and a slightly higher percentage of men than women are in medicine overseas or in medicine in Britain outside the NHS. It is conceivable that a higher percentage of women who are not in medicine than of men who are not in medicine replied to our questionnaires. If so, some of the apparent difference between women and men not working in known not to be in the NHS. This assumes that the characteristics of respondents who were not in the NHS are similar to those of the non-respondents who were not in the NHS in respect of sector of employment. 
Table 2 | Percentage $(95 \% \mathrm{Cl})$ of doctors from overseas homes who were working in the NHS in Great Britain after qualification

\begin{tabular}{|c|c|c|c|}
\hline $\begin{array}{l}\text { Years after qualification, and } \\
\text { cohort }\end{array}$ & Men & Women & Total \\
\hline \multicolumn{4}{|l|}{2 years after } \\
\hline 1988 & 77.0 (74.6 to 79.3$)$ & 66.8 (63.8 to 69.8 ) & $72.6(70.7$ to 74.5$)$ \\
\hline 1993 & 74.3 (73.0 to 75.6$)$ & 82.4 (81.0 to 83.8$)$ & 78.0 (77.0 to 79.0$)$ \\
\hline $1996^{*}$ & $62.8(60.2$ to 65.5$)$ & 75.8 (71.7 to 79.8$)$ & 68.1 (65.8 to 70.5$)$ \\
\hline $1999^{\star}$ & 76.7 (73.2 to 80.2$)$ & $76.3(69.2$ to 83.4$)$ & 75.9 (71.9 to 80.0$)$ \\
\hline 2000 & 80.6 (78.0 to 83.1$)$ & 70.8 (68.8 to 72.8$)$ & 75.5 (73.9 to 77.1$)$ \\
\hline 2002 & 79.5 (76.0 to 82.9) & 80.5 (78.6 to 82.5$)$ & $80.0(78.2$ to 81.8$)$ \\
\hline Total & 76.2 (75.0 to 77.4$)$ & 76.0 (74.7 to 77.2$)$ & 76.1 (75.2 to 76.9$)$ \\
\hline \multicolumn{4}{|l|}{5 years after } \\
\hline 1983 & 72.6 (69.4 to 75.8$)$ & 73.4 (66.7 to 80.2$)$ & $72.9(69.7$ to 76.0$)$ \\
\hline 1988 & 69.5 (65.6 to 73.4$)$ & $67.4(63.1$ to 71.7$)$ & $68.9(65.7$ to 72.0$)$ \\
\hline 1993 & 72.2 (68.1 to 76.3$)$ & 73.6 (70.0 to 77.3$)$ & $72.9(70.1$ to 75.7$)$ \\
\hline 1996 & $67.3(62.9$ to 71.7$)$ & 79.2 (63.0 to 95.5) & $70.8(65.2$ to 76.5$)$ \\
\hline 1999 & $70.0(67.6$ to 72.4$)$ & $74.0(68.0$ to 80.0$)$ & $72.0(68.7$ to 75.2$)$ \\
\hline 2000 & 79.4 (71.5 to 87.2$)$ & 67.3 (61.8 to 72.7 ) & 73.2 (68.5 to 78.0$)$ \\
\hline Total & $72.4(70.5$ to 74.4$)$ & 71.5 (68.9 to 74.2$)$ & 72.0 (70.4 to 73.6$)$ \\
\hline \multicolumn{4}{|l|}{10 years after } \\
\hline 1977 & $55.0(52.8$ to 57.1$)$ & 47.1‡ & $53.1(51.3$ to 54.8$)$ \\
\hline 1983 & 63.8 (61.6 to 66.0$)$ & $66.0(62.6$ to 69.5$)$ & $64.6(62.7$ to 66.5$)$ \\
\hline 1988 & $63.6(60.9$ to 66.3$)$ & $62.4(58.9$ to 65.9$)$ & $63.2(60.9$ to 65.4$)$ \\
\hline 1993 & $69.6(63.7$ to 75.5$)$ & 76.7 (70.2 to 83.2) & 73.2 (68.6 to 77.8$)$ \\
\hline 1996 & 56.7 (47.9 to 65.6) & $50.6(45.4$ to 55.8$)$ & $54.4(48.6$ to 60.2$)$ \\
\hline Total & $61.6(60.0$ to 63.3$)$ & $64.0(61.6$ to 66.4$)$ & 62.5 (61.2 to 63.9) \\
\hline \multicolumn{4}{|l|}{15 years after } \\
\hline 1974 & 54.7 (52.5 to 57.0$)$ & 57.3 (53.4 to 61.3) & 55.3 (53.3 to 57.3 ) \\
\hline 1977 & 49.7 (47.8 to 51.6$)$ & $50.6(47.7$ to 53.6$)$ & $50.0(48.3$ to 51.6$)$ \\
\hline 1983 & 61.7 (58.6 to 64.7$)$ & 64.7 (61.2 to 68.2$)$ & 62.8 (60.4 to 65.1$)$ \\
\hline 1988 & 62.1 (59.1 to 65.1) & $58.0(54.3$ to 61.7$)$ & $60.4(58.0$ to 62.8$)$ \\
\hline Total & $57.0(55.6$ to 58.4$)$ & 59.6 (57.4 to 61.7$)$ & $57.8(56.7$ to 59.0$)$ \\
\hline \multicolumn{4}{|l|}{20 years after } \\
\hline 1974 & 56.1 (53.5 to 58.8$)$ & 71.7 (64.7 to 78.7 ) & 59.3 (56.7 to 61.9) \\
\hline 1977 & $43.6(41.8$ to 45.4$)$ & 47.1‡ & $44.7(43.0$ to 46.4$)$ \\
\hline Total & 49.6 (48.0 to 51.2$)$ & $58.1(53.5$ to 62.7$)$ & 51.6 (49.9 to 53.2$)$ \\
\hline \multicolumn{4}{|l|}{25 years after } \\
\hline $1974 \dagger$ & 54.4 (52.6 to 56.2$)$ & 77.2 (68.3 to 86.0 ) & 59.1 (56.7 to 61.4) \\
\hline 1977 & 43.7 (41.8 to 45.6) & $38.2 \ddagger$ & $42.4(40.9$ to 43.8$)$ \\
\hline Total & 48.8 (47.5 to 50.2$)$ & 54.1 (50.4 to 57.7$)$ & $50.0(48.7$ to 51.4$)$ \\
\hline \multicolumn{4}{|l|}{27 years after } \\
\hline 1977 & $46.6(44.9$ to 48.2$)$ & $38.2 \ddagger$ & $44.5(43.2$ to 45.8$)$ \\
\hline
\end{tabular}

Results include data from most recent survey, for doctors who indicated that their family home location is abroad.

Excluded: graduates who were deceased and those who asked to be non-participants.

*Results are for year 3 for 1999 and 1996 cohorts.

tResults are for year 24 for 1974 cohort.

‡For these cohort years, for women, the number known only to MCRG was 0. A standard error cannot be calculated, and hence the $\mathrm{Cl}$ cannot be calculated.

medicine might reflect responder bias. Whether or not this is the case, the overall differences between women and men in participation rates in medicine remain small.

As expected, a much higher percentage of women than men work part time. The extent of part-time work by women, rather than whether medically qualified women will work in medicine at all, is the major

\section{WHAT IS ALREADY KNOWN}

Very little systematic information is available about the career destinations of medical graduates, including the proportion who eventually practise medicine in the country in which they trained

A common assumption is that a smaller percentage of women than men medical graduates will work in medicine in the long term

It is sometimes considered that there are increases in numbers of doctors quitting the NHS, at times when they become disenchanted with it

\section{WHAT THIS STUDY ADDS}

The great majority of British-home British-trained medical graduates worked in the NHS, eg $88 \%$ at two years after graduation, $86 \%$ at 10 years, and $82 \%$ at 20 years

The differences between men and women in this respect were negligible

The majority of medical graduates who were not in the NHS were in medicine elsewhere

The majority of doctors who trained in Britain, but who were residents outside it at entry to medical school, subsequently worked in the NHS

We did not identify any times when sharp increases in departure of doctors from the NHS occurred

factor that needs to be considered in workforce planning.

Current British immigration rules allow all doctors who were trained as medical students in Britain to remain in Britain to practise after qualification and to have equal access to jobs and training. ${ }^{10-12}$ Of doctors whose homes were outside Britain when they became medical students at British universities, the great majority worked in Britain after graduating. Twothirds were still in the NHS 10 years after qualifying.

From time to time, anecdotal evidence is put forward to suggest that doctors, disenchanted with the NHS, have started to leave it. Our evidence does not suggest that there was any period of time over the past 30 years when there was a sudden and substantial increase in loss of doctors from the NHS. Younger generations of doctors are sometimes viewed as less committed than previous generations to a working career in medical practice, but according to our evidence younger generations are as committed as their predecessors.

Acknowledgements: We thank the doctors who participated in the surveys, and we thank Emma Ayers, Janet Justice, and Alison Stockford for data preparation and administration.

Contributors: MJG and TWL planned and designed the surveys. MJG and JMD planned the data analysis. JMD undertook the data analysis. TWL provided statistical support. JMD and MJG wrote the first draft of the paper. All authors contributed to further drafts and approved the final version. All had full access to all the data in the study and had final responsibility for the decision to submit for publication, and all are guarantors.

Funding: The UK Medical Careers Research Group is funded by the Policy Research Programme of the English Department of Health. The Unit of Health Care Epidemiology is funded by the English NIHR Coordinating Centre for Research Capacity Development. 
Competing interests: None declared.

Ethical approval: Study approved by Central Office for Research Ethics Committees (COREC), after referral to Brighton Mid Sussex and East

Sussex local research ethics committees.

1 Eckhert NL. The global pipeline: too narrow, too wide or just right? Medical Education 2002;36:606-13.

2 Levinson W, Lurie N. When most doctors are women: what lies ahead? Annals of Internal Medicine 2004;141:471-4.

3 Hook EB, Regal RR. Capture-recapture methods in epidemiology: methods and limitations. Epidemiol Rev 1995;17:243-64.

4 Lambert TW, Goldacre MJ, Edwards C, Parkhouse J. Career preferences of doctors who qualified in the United Kingdom in 1993 compared with those of doctors qualifying in 1974, 1977, 1980, and 1993. BMJ 1996;313:19-24.

5 Lambert TW, Goldacre MJ. Career destinations seven years on among doctors who qualified in the United Kingdom in 1988: postal questionnaire survey. BMJ 1998;317:1429-31.

6 Goldacre MJ, Lambert TW, Davidson JM. Loss of British-trained doctors from the medical workforce in Great Britain. Medical Education 2001;35:337-44.
7 Lambert TW, Goldacre MJ, Davidson JM, Parkhouse J. Estimation of numbers of UK medical graduates working in the NHS: comparison of capture-recapture analysis and exhaustive tracing. Journal of Health Services Research and Policy 2004;9:234-6.

8 Moss P, Lambert TW, Goldacre MJ, Lee P. Reasons for considering leaving UK medicine: questionnaire study of junior doctors' comments. BMJ 2004;329:1263-5.

9 Kilminster S, et al. Women in medicine-is there a problem? A literature review of the changing gender composition, structures and occupational cultures in medicine. Medical Education 2007;41:39-49.

10 Byrne E. Should postgraduate training places be reserved for UK graduates? Yes. BMJ 2007;335:590

11 Borman E. Should postgraduate training places be reserved for UK graduates? No. BMJ 2007;335:591.

12 Workforce Directorate of the Department of Health. Modernising Medical Careers (MMC) England. Recruitment to foundation and specialist training: proposals for managing applications from medical graduates outside the European economic area. Equality impact assessment. England: Department of Health, 2008.

Accepted: 11 May 2009 